\title{
PENERAPAN K-MEANS UNTUK MENGANALISIS PENGARUH CURAH HUJAN TERHADAP PRODUKSI LISTRIK (STUDI KASUS: PT. INDONESIA POWER)
}

\author{
Alifa Hanifah', Aji Primajaya ${ }^{2}$, Agung Susilo Yuda Irawan ${ }^{3}$ \\ 1,2,3 Teknik Informatika, Fakultas Ilmu Komputer, Universitas Singaperbangsa Karawang \\ 1alifa16030@student.unsika.ac.id, ${ }^{2}$ aji.primajaya@staff.unsika.ac.id, ${ }^{3}$ agung@unsika.ac.id
}

\begin{abstract}
Abstrak
Listrik merupakan kebutuhan pokok bagi kehidupan masyarakat saat ini. Salah satu pembangkit tenaga listrik yaitu Pembangkit Listrik Tenaga Air (PLTA). Dalam sistemnya, PLTA memanfaatkan tenaga dari aliran/terjunan air, bendungan, atau saluran irigasi. Air merupakan energi utama dalam proses PLTA dan salah satu faktor dalam ketersediaan air adalah curah hujan sehingga karyawan PLTA lebih cenderung melihat curah hujan untuk menentukan target produksi listrik. K-Means merupakan metode data clustering non-hirarki yang berusaha mempartisi data yang ada ke dalam bentuk satu atau lebih cluster. Tujuan dari penelitian ini yaitu melakukan cluster terhadap produksi daya listrik dan curah hujan serta mengevaluasi hasil tersebut beruhubungan atau tidak. Nilai yang digunakan dalam penelitian ini adalah nilai hasil produksi listrik (KWH) dan curah hujan (RR). Data yang digunakan sebanyak 1826 data produksi daya listrik dan data curah hujan. Pada penelitian ini ingin menganalisis pengaruh curah hujan terhadap produksi daya listrik dengan $\mathrm{K}$-Means Clustering. Hasil dari penelitian ini adalah akurasi terhadap clustering produksi daya listrik dengan curah hujan.
\end{abstract}

Kata kunci : Clustering, Curah Hujan, K-Means, Produksi Daya Listrik

\section{Pendahuluan}

Energi listrik merupakan salah satu kebutuhan pokok masyarakat, memiliki atri penting dalam memajukan kesejahteraan umum, mencerdaskan kehidupan bangsa dan meningkatkan perekonomian (Maslichah, 2016). Dengan pesatnya pertumbuhan perindustrian, ekonomi dan teknologi informasi, dengan itu kebutuhan akan energi listrik semakin meningkat. Ketersediaan sumber energi pembangkit lisrik dalam pemanfaatan sumber energi diatur dalam UU 30 Tahun 2009 Pasal 2 Tentang Ketenagalistrikan. Di Indonesia terdapat bebagai macam pembangkit listrik berdasarkan sumber energi nya yaitu: Pembangkit Listrik Tenaga Air (PLTA), Pembangkit Listrik Tenaga Surya (PLTS), Pembangkit Listrik Tenaga Gas (PLTG), Pembangkit Listrik Tenaga Panas Bumi (PLTP), dan masih banyak lagi.

Menurut Badan Pusat Statistik, provinsi Jawa Barat menempati urutan ke 4 sebagai provinsi penghasil listrik atau tenaga listrik yang dibangkitkan dengan satuan Giga Watt Hour (GWh) terbanyak di Indonesia dalam 6 tahun yaitu pada tahun 2011, 2012, 2013, 2014, 2015, dan 2017 produksi listrik di provinsi Jawa Barat memiliki nilai yang fluktuatif atau memiliki penghasil listrik yang naik turun pada setiap tahunnya. Untuk nilai produksi listrik tiap tahunnya di provinsi Jawa Barat yaitu sebanyak 16089.53 GWh (Giga Watt Hour) pada tahun 2011, 17378.85 GWh (Giga Watt Hour) pada tahun 2012,
21615.84 GWh (Giga Watt Hour) pada tahun 2013, 20849.37 GWh (Giga Watt Hour) pada tahun 2014, 20617.92 GWh (Giga Watt Hour) pada tahun 2015, dan 37801,93 GWh (Giga Watt Hour) pada tahun 2017, dari 6 tahun tersebut hasil produksi listrik terbesar di provinsi Jawa Barat yaitu pada tahun 2017 sebesar 37801,93 Gwh (Giga Watt Hour).

Pembangkit Listrik Tenaga Air (PLTA) merupakan salah satu pembangkit listrik yang terdapat di provinsi jawa barat. Menurut Peraturan Menteri Energi dan Sumber Daya Mineral tentang Pemanfaatan Sumber Energi Terbarukan untuk Penyediaan Tenaga Listrik pada BAB 1 Pasal 1 Ayat 10 Pembangkit Listrik Tenaga Air yang selanjutnya disebut Tenaga Air adalah pembangkit listrik yang memanfaatkan tenaga dari aliran/terjunan air, waduk/bendungan, atau saluran irigasi yang pembangunannya bersifat multiguna.

Air merupakan energi utama dalam proses Pembangkit Listrik Tenaga Air dan salah satu faktor penentu dalam ketersedian air adalah curah hujan. Curah hujan merupakan ketinggian air hujan yan terkumpul dalam tempat yang datar, tidak menguap, tidak meresap dan tidak mengalir. Curah hujan juga didefinisikan sebagai tinggi air $(\mathrm{mm})$ yang diterima permukaan sebelum mengalami aliran permukaan, evaporasi dan peresapan kedalam tanah. Curah hujan merupakan salah satu faktor dalam ketersedian air dan air digunakan untuk menjalankan turbin dalam Pembangkit Listrik Tenaga Air. (Desvina \& Ratnawati, 2014) 
K-Means sendiri merupakan salah satu metode data clustering non-hirarki yang berusaha mempartisi data yang ada ke dalam bentuk satu atau lebih cluster/kelompok. Metode ini mempartisi data ke dalam cluster/kelompok sehingga data yang memiliki karakteristik sama dikelompokkan ke dalam satu cluster yang sama (Metisen \& Sari, 2015). Kelebihan dari algoritma K-Means adalah mampu mengelompokkan objek besar dengan sangat cepat sehinga mempercepat proses pengelompokkan. Selain itu, pada algoritma $K$-Means proses iterasi akan berhenti dalam keadaan optimum (Poerwanto \& Fa'rifah, 2019). Pada penelitian ini pengaruh curah hujan dan produksi daya listrik dapat diketahui dengan melihat hasil dari clustering pada kedua dataset menggunakan K-Means clustering.

Penelitian yang dilakukan oleh (Rohi \&

Tumbelaka, 2017) mengenai studi kinerja Pembangkit Listrik Tenaga Air (PLTA) menghasilkan kesimpulan bahwa debit ait inflow sangat berpengaruh pada besarnya capacity factor dan daya.

Atas dasar itulah, penulis ingin melakukan penelitian tentang ANALISIS PENGARUH CURAH HUJAN TERHADAP PRODUKSI DAYA LISTRIK DENGAN K-MEANS CLUSTERING (Studi Kasus: PT. Indonesia Power)

\section{Landasan Teori}

\subsection{Listrik}

Energi listrik adalah kemampuan untuk atau menghasilkan usaha listrik (kemampuan yang diperlukan untuk memindahkan muatan dari satu titik ke titik yang lain), dilambangkan dengan $\mathrm{W}$ (Melipurbowo, 2016).

\subsection{Pembangkit Listrik Tenaga Air (PLTA)}

Pembangkit listrik Tenaga Air (PLTA) adalah pembangkit listrik yang memanfaatkan tenaga (aliran) air sebagai sumber penghasil energi. PLTA termasuk sumber energi terbarukan dan layak disebut clean energy karena ramah lingkungan (Rahmadi, Yusuf, \& Priyatman, 2015).

\subsection{Curah Hujan}

Curah hujan merupakan ketinggian air hujan yang terkumpul dalam tempat yang datar, tidak menguap, tidak meresap, dan tidak mengalir. Satuan curah hujan selalu dinyatakan dalam satuan millimeter atau inchi namun untuk di Indonesia satuan curah hujan yang digunakan adalah satuan millimeter (mm) (Ajr \& Dwirani, 2019).

\subsection{Data Mining}

Data mining adalah proses mencari pola atau informasi menarik dalam data terpilih dengan menggunakan teknik atau metode tertentu. Teknik, metode, atau algoritma dalam data mining sangat bervariasi. Pemilihan metode atau algoritma yang tepat sangat bergantung pada tujuan dan proses KDD secara keseluruhan (Putra \& Wadisma, 2018).

\subsection{Imputasi}

Metode imputasi adalah pengisian nilai data nilai pada suatu survei. Imputasi juga merupakan suatu alternative dalam menangani permasalahan missing data dalam analisis statistik. Terdapat beberapa macam pendekatan untuk imputasi (Sartika, 2018).

\subsection{Normalisasi Min-Max}

Min-Max normalization atau normalisasi minmax merupakan metode normalisasi dengan melakukan transformasi linier terhadap data asli sehingga menghasilkan keseimbangan nilai perbandingan antar data saat sebelum dan sesudah proses (Nasution, Khotimah, \& Chamidah, 2019).

\subsection{Clustering}

Clustering adalah pengelompokan dari record, observasi-observasi atau kasus-kasus ke kelas yang memiliki kemiripan pada objek-objeknya. Cluster adalah koleksi dari record yang mirip, dan tidak mirip dengan record dari cluster lain (Halim \& Widodo, 2017).

\subsection{Algoritma K-Means}

K-Means merupakan salah satu metode data clustering non hierarki yang berusaha mempartisi data yang ada ke dalam bentuk satu atau lebih cluster atau kelompok sehingga data yang memiliki karakteristik yang sama dikelompokkan ke dalam satu cluster yang sama dan data yang mempunyai karakteristik yang berbeda di kelompokkan ke dalam kelompok yang lainnya(Metisen \& Sari, 2015).

\subsection{Metode Elbow}

Metode Elbow merupakan suatu metode yang digunakan untuk menghasilkan informasi dalam menentukan jumlah cluster terbaik dengan cara melihat persentase hasil perbandingan antara jumlah cluster yang akan membentuk siku pada suatu titik (Merliana, Ernawati, \& Santoso, 2015).

\subsection{Weka}

Weka merupakan rangkaian perangkay lunak pembelajaran mesin yang ditulis dalam bahasa Java, dikembangkan di Universitas Waikato, Selandia 
Baru. Perangkat lunak ini memiliki banyak algoritma machine learning untuk keperluan data mining. Weka juga memiliki banyak tool untuk pengolahan data, mulai dari data preprocessing, classification, association rules, dan visualization (Faid, Jasri, \& Rahmawati, 2019).

\section{Metodologi Penelitian 3.1 Objek Penelitian}

Objek dalam penelitian ini yaitu data curah hujan di Kabupaten Bogor dan data produksi listrik setiap harinya dari bulan Januari 2015 hingga bulan Desember 2019 pada Pembangkit Listrik Tenaga Air di PT. Indonesia Power.

\subsection{Metode}

Penelitian ini menggunakan metode knowledge discovery in database. merupakan suatu proses persimpangan dari beberapa disiplin ilmu seperti statistik, database, AI, visualisasi dan komputer parallel yang mempengaruhi pengetahuan (Ependi \& Putra, 2019). Adapun alur penelitian dapat dilihat pada Gambar 1.

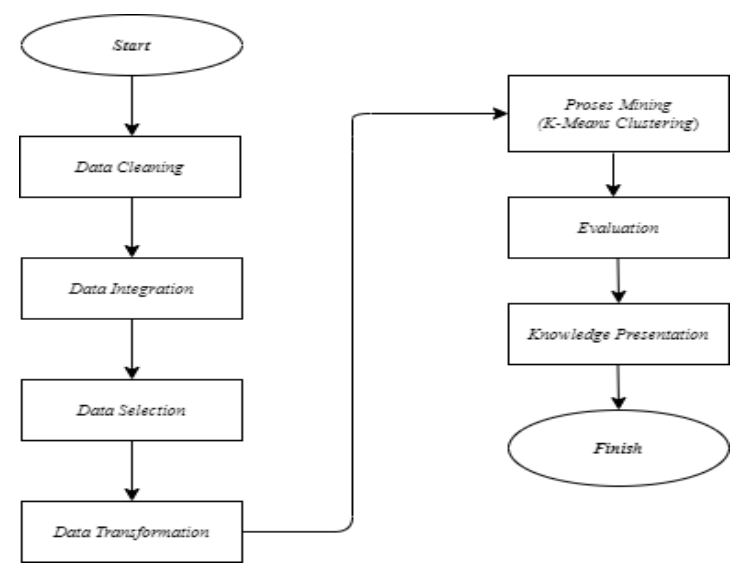

Gambar 1. Alur Penelitian

\section{a. Data Cleaning}

Data cleaning adalah membersihkan data dari data yang tidak konsisten dan bersifat noise karena secara umum data yang tersedia pada database memiliki isian-isian yang tidak sempurna karena hilang ataupun tidak valid.

b. Data Integration

Data Integration mengintegrasikan data dari berbagai sumber, dimana integrasi data ini dilakakuan pada data-data yang memiliki atribut yang unik.

c. Data Selection

Data Selection merupakan data yang ada pada database yang sering kali tidak dipakai semuanya, oleh karena itu hanya data yang sesuai untuk dianalisis yang akan diambil dari database.

d. Data Transformation
Pada tahapan data transformation yaitu mentransformasikan data agar sesuai dengan kebutuhan Data Mining.

e. Data Mining

Pada proses Data Mining ini merupakan proses utama pada saat metode diterapkan untuk menemukan pengetahuan berharga dan tersembunyi dari data.

\section{f. Evaluation}

Pada tahapan ini diharapkan adanya hasil berupa pola yang unik yang dapat digunakan sebagai model untuk memprediksi perilaku-perilaku bisnis yang sekiranya akan mempengaruhi sebuah kepurusan manajemen.

\section{g. Knowledge}

Tahapan terakhir ini merangkum dan menerjemahkan analisis dan merangkum hasil analisis yang terlah didapat dengan bahasa yang semudah mungkin karena melibatkan orang lain pada manajemen yang kemungkinan besar awam dengan Data Mining.

\section{Hasil Penelitian}

\subsection{Data Cleaning}

Pada tahapan data cleaning dilakukan pembersihan data dari missing value dan outlier agar kualitas data menjadi semakin baik untuk diolah. Pada tahapan ini akan dilakukan cleaning pada dataset Hasil Produksi Listrik dan dataset Curah Hujan. Pada tahap ini dilakukan proses cleaning pada seluruh atribut yang memiliki missing value data tersebut akan diganti menjadi data hasil imputasi mean.

\subsection{Data Integration}

Data Intergration merupakan tahapan mengintegrasikan seluruh data, kemudian digabungkan menjadi satu dataset. Dalam dataset Hasil Produksi Listrik PT. Indonesia Power Sub Unit PLTA Kracak dan dataset Curah Hujan di Bogor berasal dari satu sumber yang sama, namun dataset tersebut terdiri dari beberapa file yang berbeda, sesuai dengan bulan dan tahun pencatatan datanya.

\subsection{Data Selection}

Proses pre processing dilakukan untuk memperoleh citra yang selanjutnya dapat Data Selection merupakan tahap pemilihan data dari sekumpuan data yang berada pada tabel, tidak semua data dipakai, hanya yang relevan pada database sesuai dengan kebutuhan, karena tidak semua data cocok untuk digunakan. Pada penelitian ini data Hasil Produksi Listrik didapat dari PT. Indonesia Power Sub Unit PLTA Kracak dan data Curah hujan didapat 
dari Data Online Pusat Database Badan Meteorologi, Klimatologi, dan Geofisika (BMKG).

\subsection{Data Transformation}

Tahap transformasi adalah tahap mengubah atau mentransformasikan bentuk dataset agar sesuai dengan kebutuhan data mining dan dapat diolah menggunakan metode K-Means Clustering. Pada tahap transformasi dilakuan normalisasi terhadap data dengan pengskalaan nilai atribut dari data sehingga bisa jatuh pada range tersebut dengan metode normalisasi Min-Max dengan melakukan transformasi linier terhadap data asli. Metode ini dapar menggunakan rumus sebagai berikut :

$$
\text { Newdata }=\frac{(\text { data }-\min ) \mathrm{x}(\text { newmax }- \text { newmin })}{(\max -\min )+\text { newmin }}
$$

Newdata $=$ Data hasil normalisasi

Min $=$ Nilai minimum dari data per kolom

Max = Nilai maksimum dari data per kolom

Newmin = Batas minimum yang kita berikan

Newmax $=$ batas maksimum yang kita berikan

\subsection{Data Mining}

Setelah melakukan tahap transformasi data menjadi data yang sesuai untuk penerapan data mining yang akan dilakukan pemilihan teknik algoritma untuk menemukan pola atau informasi dalam pengelompokkan Curah Hujan dan Jumlah Hasil Produksi Listrik. Pada penelitian ini, menggunakan metode Clustering dengan algoritma $K$-Means dengan proses clustering menggunakan $\mathrm{K}=3$ dengan seed 10 .

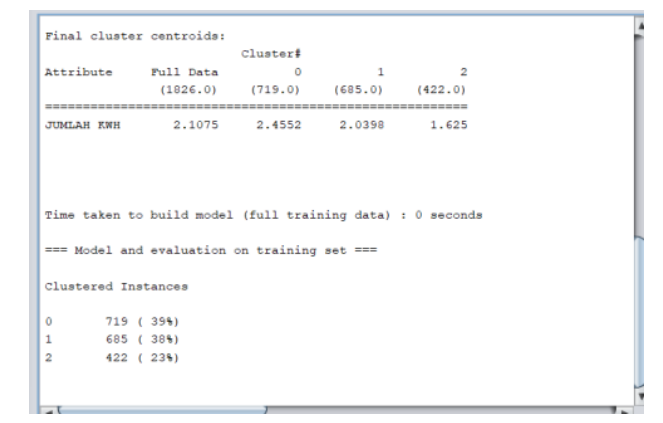

Gambar 2. Hasil cluster Produksi Listrik Tahun 2015-2019

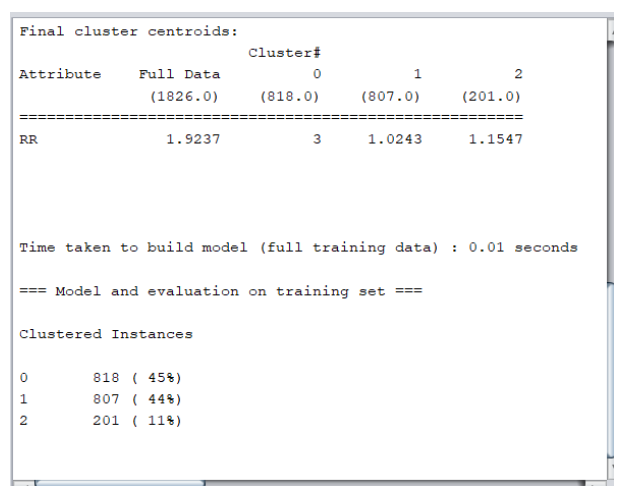

Gambar 3. Hasil Cluster Curah Hujan Tahun 20152019

\subsection{Evaluation}

Pada penelitian ini menggunakan metode Elbow untuk menghasilkan informasi dalam menentukan jumlah cluster terbaik dengan cara melihat persentase hasil perbandingan antara jumlah cluster yang akan membentuk siku pada suatu titik. Untuk mendapatkan perbandingannya dilakukan pengujian data menggunakan Sum of Square Eror untuk menentukan data menjadi data yang sesuai. Pada penelitian sebelumnya dilakukan pengujian terhadap cluster dari $\mathrm{K}=2$ sampai dengan $\mathrm{K}=8$ untuk menentukan jumlah $\mathrm{k}$ terbaik dan menghasilkan $\mathrm{K}=3$ sebagai cluster terbaik (Merliana et al., 2015).

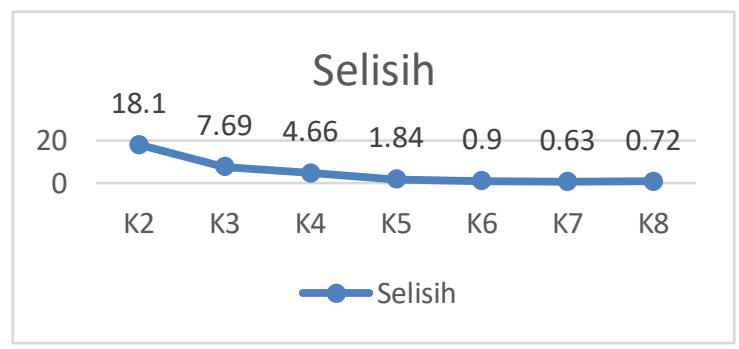

Gambar 4. Grafik Sum of Square Error Hasil Produksi Listrik

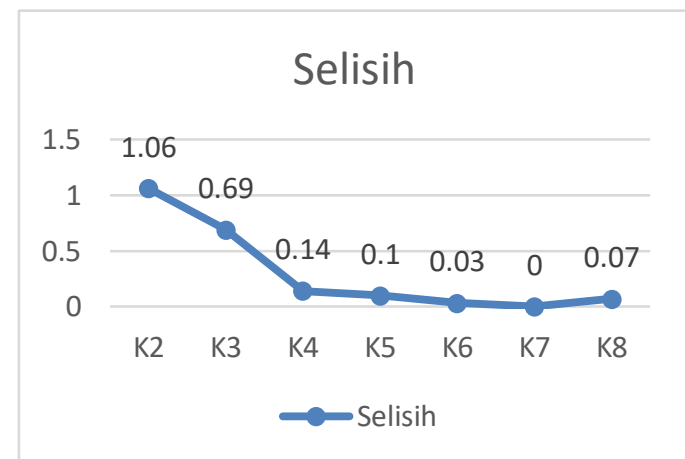

Gambar 5. Grafik Sum of Square Error Curah Hujan

Berdasarkan hasil dari grafik Sum of Square Error tersebut didapat nilai yang mengalami penutunan disetia perubahan cluster. Analisis dalam penentuan jumlah $\mathrm{K}$ optimal menggunakan metode 
Elbow dengan perhitungan SSE berdasarkan hasil percobaan tersebut dengan melihat penutunan selisih nilai Sum of Square Error yang signifikan dan berbentuk siku diperoleh jumlah cluster optimal 3.

\subsection{Knowledge}

Berdasarkan hasil dari evaluasi cluster yang telah terbentuk melalui proses evaluasi dengan metode Sum of Error (SSE) maka didapat pengetahuan baru sebagai berikut :

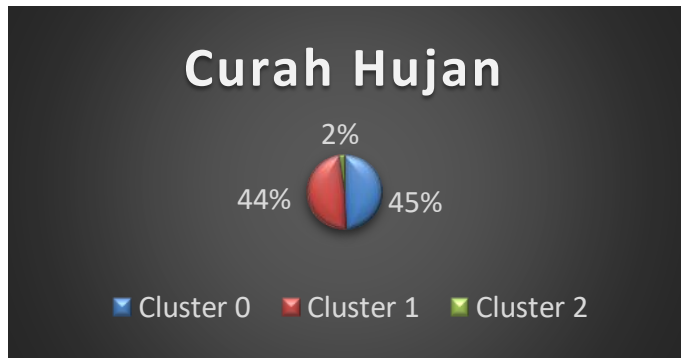

Gambar 6. Hasil Presentasi Cluster pada Dataset Curah Hujan

Pada diagram diatas, dapat dilihat bahwa Cluster 2 memiliki anggota paling sedikit. Berdasarkan tabel hasil clustering, dapar dilihat hasil produksi listrik yang terasuk ke dalam Cluster 0 sebagian besar memiliki frekuensi tinggi (curah hujan tinggi), cluster 1 memiliki frekuensi curah hujan yang rendah dan Cluster 2 memiliki sebagian frekuensi curah hujan sedang. Oleh karena itu, curah hujan cluster 0 dapat dikategorika tinggi, cluster 2 dapat dikategorikan sedang dan cluster 1 dapat diketegorikan rendah.

\section{Hasil Produksi Listrik}

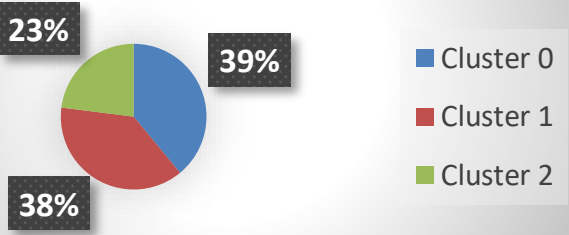

Gambar 7. Hasil Presentasi Cluster pada Dataset Curah Hujan

Pada diagram diatas, dapat dilihat bahwa Cluster 0 memiliki anggota paling banyak. Berdasarkan tabel hasil clustering, dapat dilihat hasil produksi listrik yang termasuk ke dalam Cluster 2 sebagian besar memiliki frekuensi hasil produksi terendah (hasil produksi listriknya rendah), Cluster 1 sebagian besar memiliki frekuensi hasil produksi listrik sedang dan Cluster 0 memiliki sebagian besar frekuensi hasil produksi listrik tinggi. Oleh karena itu, hasil produksi listrik Cluster 0 dapat dikategorikan tinggi, Cluster 1 dapat dikategorikan sedang, dan Cluster 2 dikategotikan rendah.
Berdasarkan hasil cluster terhadap data Hasil Produksi Listrik yang didapat dari PT. Indonesia Power dan data Curah Hujan yang didapat dari Data Online Pusat Database Badan Meteorologi, Klimatologi, dan Geofisika (BMKG. Dalam 5 tahun terakhir atau pada tahun 2015 hingga 2019 data hasil clustering menunjukkan hasil data kesamaan dengan menlihat data hasil cluster antara hasil produksi listrik dan curah hujan adalah seperti pada gambar di bawah ini.

\section{Hubungan Antara Produksi Llstrik dan Curah Hujan}
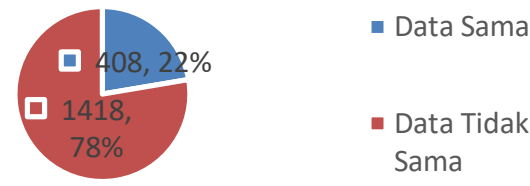

Gambar 8. Grafik Perbandingan Produksi Listrik dan Curah Hujan

Dari grafik diatas didapatkan hasil produksi listrik dan curah hujan hanya sebanyak $22 \%$ atau sebanyak 408 memiliki data hasil clustering yang sama dan hasil produksi listrik dan hujan yang tidak sama adalah 78\% atau sebanyak 1418 data. Pada pengamatan yang telah penulis lakukan di PT. Indonesia Power Sub Unit PLTA Kracak ada faktor lain yang mempengaruhi hasil produksi listrik yaitu mesin yang berfungsi dengan baik atau tidak.

\section{Kesimpulan dan Saran}

\subsection{Kesimpulan}

Berdasarkan hasil penelitian yang telah dilaksanakan maka didapatkan kesimpulan sebagai berikut:

1. Hasil Produksi Listrik di PT Indonesia Power dan Curah Hujan BMKG dengan menggunakan algoritma K-Means Clustering dalam proses pengolahan datanya dan menggunakan Metode Elbow dengan perhitungan Sum Square of Error dalam proses evaluasi dataset menghasilkan 3 cluster. Secara keseluruhan dalam tahapan data mining pada penelitian ini dibantu dengan tools WEKA 3.8.4.

2. Secara keseluruhan hasil dari evaluasi menggunakan Metode Elbow dengan perhitungan Sum Square of Error menunjukkan bahwa hasil dari cluster Hasil Produksi Listrik pada PT. Indonesia Power dan cluster Curah Hujan menunjukkan hasil yang $22 \%$ memiliki data hasil cluster yang sesuai dan $78 \%$ memiliki data yang tidak sesuai atau sebanyak 1826 data hasil produksi listrik hanya sebanyak 408 data yang sesuai dengan curah hujan sisanya sebanyak 1418 data hasil produksi listrik tidak 
sesuai dengan curah hujan. Hasilnya ditunjukkan pada grafik yang telah dijelaskan pada tahapan Knowledge. Hal tersebut menentukan bahwa curah hujan sebagai salah satu faktor yang mempengaruhi debit air tidak berpengaruh terhadap hasil dari produksi daya listrik namun ada faktor lain yang perlu dimasukkan dalam pembuatan model karena akan mempengaruhi hasil dari clustering .

\subsection{Saran}

Dari hasil penelitian yang telah dilakukan, maka saran yang diberikan untuk referensi penelitian selanjutnya yaitu:

1. Diharapkan pada penelitian selanjutnya dapat menggunakan scenario lain untuk clustering yang lebih baik untuk proses clustering untuk mengetahui pengaruh curah hujan terhadap produksi listrik.

2. Penelitian ini hanya dilakukan di satu Pembangkit Listrik Tenaga Air (PLTA), diharapkan pada penelitian selanjutnya dilakukan pada lebih dari satu Pembangkit Listrik tenaga Air (PLTA)

\section{Daftar Pustaka:}

Ajr, E. Q., \& Dwirani, F. (2019). Menentukan stasiun hujan dan curah hujan dengan metode polygon thiessen daerah kabupaten lebak. Jurnal Lingkungan Dan Sipil, 2(2), 139-146.

Desvina, A. P., \& Ratnawati. (2014). Penerapan model vector autoregressive (VAR) untuk peramalan curah hujan kota pekanbaru. Jurnal Sains, Teknologi Dan Industri, 11(2), 151-159.

Ependi, U., \& Putra, A. (2019). Solusi prediksi persediaan barang dengan menggunakan algoritma apriori (studi kasus: regional part depo auto 2000 palembang). Jurnal Edukasi Dan Penelitian Informatika (JEPIN), 5(2), 139-145. https://doi.org/10.26418/jp.v5i2.32648

Faid, M., Jasri, M., \& Rahmawati, T. (2019). Perbandingan kinerja tool data mining weka dan rapidminer dalam algoritma klasifikasi. Teknika, 8(1), 11-16. https://doi.org/10.34148/teknika.v8i1.95

Halim, N. N., \& Widodo, E. (2017). Clustering dampak gempa bumi di indonesia menggunakan kohonen self organizing maps. Prosiding SI MaNIS (Seminar Nasional
Integrasi Matematika Dan Nilai Islami), 1(1), 188-194.

Maslichah, K. (2016). Hemat energi listrik studi kasus di badan diklat provinsi banten. Jurnal Lingkar Widyaiswara, 3(1), 47-52. Retrieved from

http://juliwi.com/published/E0301/Juliwi0301 -47-52.pdf

Merliana, N. P. E., Ernawati, \& Santoso, A. J. (2015). Analisa penentuan jumlah cluster terbaik pada metode k-means clustering. Prosiding Seminar Nasional Multi Disiplin Ilmu \& Call For Paper UNISBANK (SENDI_U), 978-979.

Metisen, B. M., \& Sari, H. L. (2015). Analisis clustering menggunakan metode k-means dalam pengelompokkan penjualan produk pada swalayan fadhila. Jurnal Media Infotama, 11(2), 110-118.

Nasution, D. A., Khotimah, H. H., \& Chamidah, N. (2019). Perbandingan normalisasi data untuk klasifikasi wine menggunakan algoritma k-nn. Computer Engineering, Science and System Journal, 4(1), 78. https://doi.org/10.24114/cess.v4i1.11458

Poerwanto, B., \& Fa'rifah, R. Y. (2019). Algoritma $\mathrm{k}$-means dalam mengelompokkan kecamatan di tana luwu berdasarkan produktifitas hasil pertanian. Journal of Chemical Information and Modeling, 53(9), 1689-1699. https://doi.org/10.1017/CBO9781107415324.0 04

Putra, R. R., \& Wadisma, C. (2018). Implementasi data mining pemilihan pelanggan potensial menggunakan algoritma k-means. Journal of Chemical Information and Modeling, 53(9), 1689-1699.

https://doi.org/10.1017/CBO9781107415324.0 04

Rahmadi, J., Yusuf, I., \& Priyatman, H. (2015). Studi kelayakan pemanfaatan pembangkit listrik kincir air terapung desa ella hilir kecamatan ella hilir kabupaten melawi. Jurnal ELKHA, 7(1), 11-18.

Rohi, D., \& Tumbelaka, H. H. (2017). Studi kinerja pembangkit listrik tenaga air (plta) di daerah aliran sungai (das) brantas. Jurnal Teknik Elektro, 10(1), 17-23. https://doi.org/10.9744/jte.10.1.17-23

Sartika, E. (2018). Analisis metode k nearest neighbor imputation (knni) untuk mengatasi data hilang pada estimasi data survey. TEDC, 12(3), 219-227. 